\section{The brain size/IQ debate}

SIR - Some of your correspondents ${ }^{1-3}$ minimize observed race differences in brain size. But such differences are often observed even before statistical correction and the IQ-brain size relationship is robust even among children.

In my US military study ${ }^{4}$, Asian Americans had larger uncorrected cranial capacities than African Americans across all male/female, officer/enlisted categories despite being shorter in stature and lighter in weight. Racial differences show up early in life. In a US national study, 17,000 white infants and 7-yearolds had significantly larger head perimeters than their 19,000 black counterparts even though, by 7 years, black children were taller and heavier ${ }^{5}$. In all groups, head perimeter at birth and at age 7 correlated with IQ at age 7 from 0.10 to 0.20 . Small differences in brain volume can translate into millions of excess neurons ${ }^{6}$.

Brand $^{3}$ claimed that nothing of any theoretical significance has been learned. But brain size has become the main constraint in primate life history theory ${ }^{7,8}$. I have proposed that these theories explain measured differences among human populations ${ }^{9}$.

\section{J. Philippe Rushton}

University of Western Ontario,

Department of Psychology,

Social Science Centre,

London, Ontario,

Canada N6A 5C2

SIR - It is indisputable that men's brains are, on average, larger than those of women. Data from Ho et al. ${ }^{10}$, show that at the age of 25 , when human brains are at maximum size, brains of men weigh about $175 \mathrm{~g}$ (17 per cent) more than those of women. This large sexdifference in brain mass has long been attributed to the larger body size of men. My analyses ${ }^{11}$ have shown (as have, ironically, those of Schluter ${ }^{1}$ ) that this explanation is false. Statistically, less than 15 per cent of variation in brain mass among men and among women is explained by variation in body size. Clearly, most brain-size variation in humans is due to something other than body size.

Surely, no one would claim that the sex-difference in brain size is due to, for example, girls having poorer nutrition than do boys in North America or Western Europe. Therefore, I propose that the difference is genetically based and probably mediated by the male sexhormone testosterone (which is responsible for many other sex differences). Only further research can refute my hypothesis that the sex-difference in brain size is related to men's, on aver-

\section{P.-L. Chau}

age, greater spatial and mathematical reasoning abilities.

\section{Davison Ankney}

\section{Department of Zoology,}

University of Western Ontario,

London, Ontario N6A 5B7, Canada

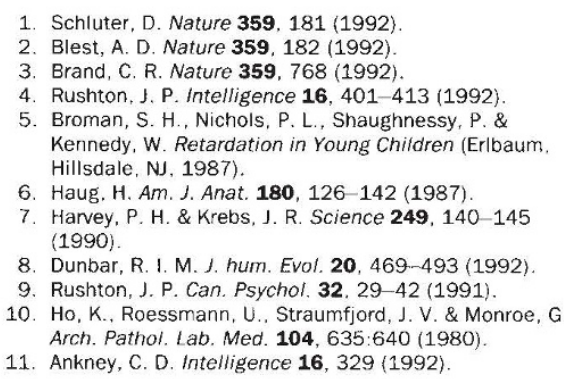

1. Schluter, D. Nature 359, 181 (1992)

2. Blest, A. D. Nature 359, 182 (1992).

3. Brand, C. R. Nature 359, 768 (1992)

4. Rushton, J. P. Intelligence 16, 401-413 (1992)

5. Broman, S. H. Nichols, P. L Shaughnessy, P. \&

Kennedy, W. Retardation in Young Children (Erlbaum Hillsdale, NJ. 1987).

6. Haug. H. Am. J. Anat. 180, 126-142 (1987)

7. Harvey, P. H. \& Krebs, J. R. Science 249, 140-145 (1990).

8. Dunbar, R. I. M. J. hum. Evol. 20, 469-493 (1992)

9. Rushton, J. P. Can. Psychol. 32. 29-42 (1991)

10. Ho, K.. Roessmann, U.. Straumfjord, J. V. \& Monroe, G Arch. Pathol. Lab. Med. 104, 635:640 (1980)

11. Ankney, C. D. Intelligence 16, 329 (1992)

This correspondence is now closed. - Editor, Nature.

\section{Human rights}

SIR - The author of the News article "Chinese scientist arrested for entrepreneurial spirit" (Nature 359, 763; 1992) suggests that "clearly, what is needed is an ongoing educational campaign about the value of knowledge". What is lacking in China is a proper judicial system where human rights are respected. In a totalitarian political system where the law courts are just the tools of the ruling Communist party, one cannot expect the judiciary to respect the rights of any individual, and certainly not scientists. Clearly what is needed is a campaign to educate the whole country, especially the government, about the idea of law, and the institution of an effective legal system independent of any political party.

University of Cambridge, Department of Pharmacology,

Cambridge CB2 1QJ, UK

SIR - As a Chinese student, I wish to point out that the "relaxed rules for visiting citizens" by the Chinese authorities (see Nature 358, 98; 1992) do not apply to Chinese citizens abroad. In particular, these rules do not apply to those once involved in the democratic movements of Chinese students and scholars. Thus a Chinese student at Harvard University, Ms Gong Xiaoxia, was expelled by the police when she arrived in Guangzhou to visit her family on 28 May. Moreover, the rules do not apply to Chinese students and scholars sent by the Chinese government but to visiting citizens who hold 'private passports'.

\section{H. Yang}

University of California, Los Angeles,

Los Angeles, California 90024, USA

\section{Climate change}

SIR - The Earth Summit in Rio de Janeiro and the earlier struggle for a Convention on Climate Change may serve as a reminder that the 1982 Convention on the Law of the Sea has its tenth anniversary on 10 December. It is not only one of the most comprehensive and strongest international treaties ever negotiated but the best possible legal means to protect the global climate. But sadly, there has been little interest in using it for this purpose. For too long, climate has been defined as the average weather and Rio was not able to define it at all. Instead, the Climate Change Convention uses the term 'climate system', defining it as "the totality of the atmosphere, hydrosphere, biosphere and geosphere and their interactions". All that this boils down to is "the interactions of the natural system'. What is the point of a legal term if it explains nothing?

For decades, the real question has been who is responsible for the climate. Climate should have been defined as 'the continuation of the oceans by other means'. Thus, the 1982 Convention could long since have been used to protect the climate. After all, it is the most powerful tool with which to force politicians and the community of states into actions.

Arnd Bernaerts

Jungfernstieg 41 ,

2000 Hamburg 36 ,

Germany

\section{Watch that dog!}

SIR - Diane Gershon (Nature 358, 614; 1992) discusses the allegation that use of recombinant bovine growth hormone (rbGH) would result in increased use of antibiotics to treat bovine mastitis "and therefore higher antibiotic residues in meat and milk". This is unlikely. Cows being treated for mastitis are not used for beef, and their milk cannot be marketed during the treatment period or for several days afterwards. The matter was resolved many years before the advent of $\mathrm{rbGH}$.

In this and another recent story ( $\mathrm{Na}$ ture 358, 4; 1992), Jeremy Rifkin's group is described as a "consumer watchdog". Rifkin's various anti-technology campaigns should be viewed in the light of his avowed objective, repeatedly stated in his books, that the world population should be reduced to one billion and that work should revert to human and animal labour

\section{Thomas H. Jukes}

University of California, Berkeley,

6701 San Pablo Avenue,

Oakland,

California 94608, USA 